City University of New York (CUNY)

CUNY Academic Works

2020

\title{
INTEGRATING DIGITAL TOOLS IN REMOTE LEARNING TO ENHANCE THE DELIVERY METHODS OF TECHNICAL CONTENT IN UNDERGRADUATE GEOSCIENCES
}

\author{
Ruslana Baker \\ Arizona State University \\ Malek Shami \\ cUNY York College \\ Nazrul I. Khandaker \\ cUNY York College \\ Stanley Schleifer \\ CUNY York College
}

\section{How does access to this work benefit you? Let us know!}

More information about this work at: https://academicworks.cuny.edu/yc_pubs/292

Discover additional works at: https://academicworks.cuny.edu

This work is made publicly available by the City University of New York (CUNY).

Contact: AcademicWorks@cuny.edu 
Integrating Digital Tools in Remote Learning to Enhance the Delivery Methods of Technical Contact in Undergraduate Geosciences BAKER, Ruslana $a^{2}$. SHAMI, Malek ${ }^{1}$.KHANDAKER, Nazrul I I'.SCHLEIFER, Stanley ${ }^{1}$

ica, NY 1145

Abstract

The global transition to remote learning due to the COVID-19 pandemic was an extremely difficult task for both students and faculty in geological sciences. Technical courses, such as Structural Geology Mineralogy, Petrology, and Invertebrate Paleontology, that require in-person lectures and laborator sessions involving various rocks and mineral samples, fossils, maps, and models, were a major concer at the start. The challenge of delivering the technical content via Microsoft Teams, Skype, WebEx Blackboard Collaborate Ultra, Zoom, and other internet based platforms was not only a burden for th faculty to carry, as students were struggling to conceptualize outcrop-and-type-section-based informatic and link these to pertinent geological phenomena dealing with depositional environment, provenance an diagenesis. Traditional classroom teaching heavily depends on signature samples and scaled mode Eath Pro, and 3D s. 3D sced The City anong he students enrolled in gateway geology courses mentioned above at York College The City University of New York - revealed that not only was the delivery of the content effective for th most part, students managed to comprehend the conceptual aspects of various plate tectonic processes key deformational features, association of mineral(s) and rock types with particular tectonic setting, po depositional and geomorphological changes on both a micro- and - macroscalc

\section{Digital Platforms}

As previously noted, the transition to digital platforms was an extraordinary challenge particularly f courses that require in person sessions. The sudden shift into remote prompted a immediate adaptation t online platforms such as WebEx, Zoom, Skype, Microsoft Teams, Adobe Connect, and Blackboarc
Collaborate Ultra. Out of all the options, Blackboard Collaborate Ultra was utilized the most for due to Collaborate Ultra. Out of all the options, Blackboard Collaborate Ultra was unilized the most for due its efficiency and familiarity with both the faculty and students. Zoom was also utilized as a backup pla
Meeting Types

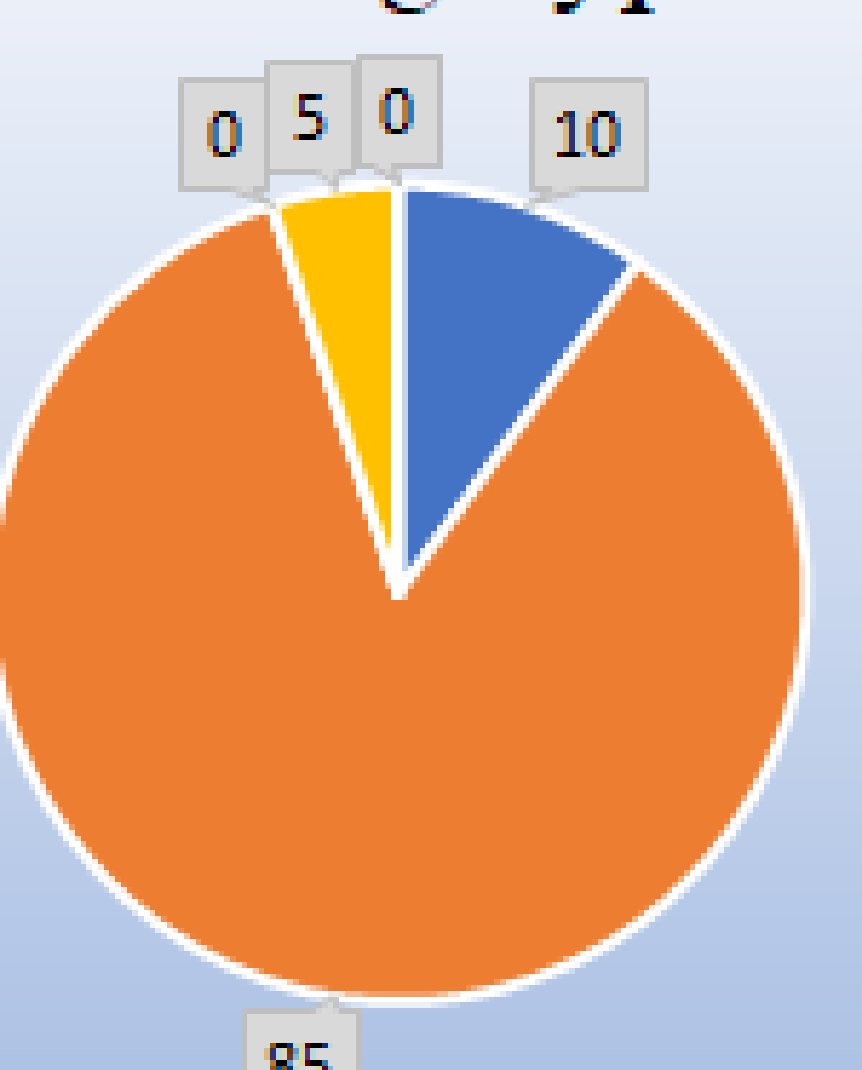

Adobe Connect $\square$ BlackBoard

$\square$ Adobe Connect $\square$ Microsoft Tean
$\square$ Skype $\quad$-Cisco Weber

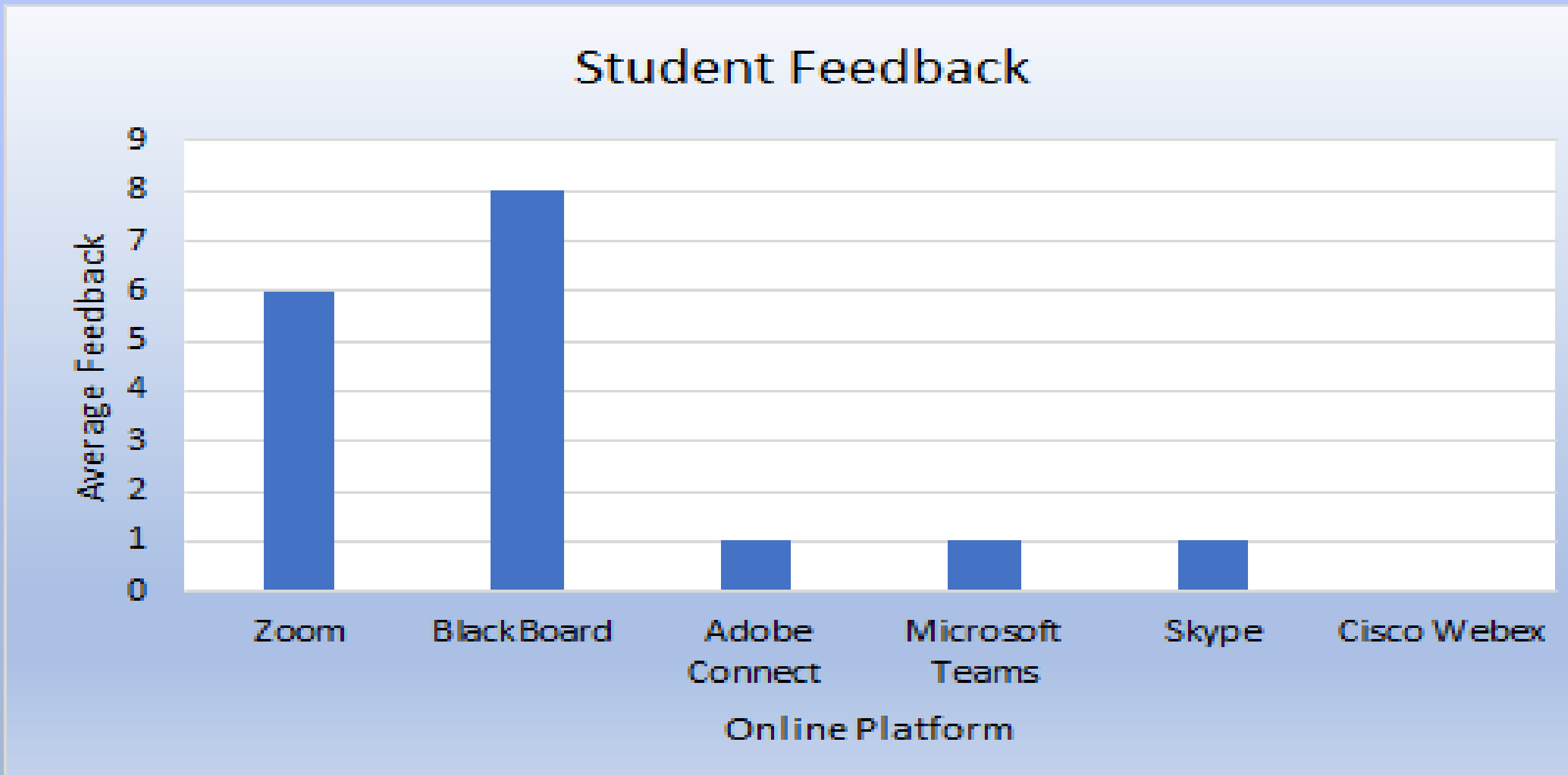

Figure. 2 - Student Feedback to Various Web Platforms

After multiple trials and errors with different platforms, students generally preferred Blackboard collaborate ultra due to thei relatively low technical issues, ability to have clear recording. Figure 1- Mode of Content Delivery and all the other features that other platform provide.

\section{The Adaptive Transition}

The transition of structural geology, a course traditionally taught in person and relied on field trips and outdoors activities, into remote learning posed a challenge for all parties involved. At the start, students were struggling to conceptualize the various structural and deformational feature and faculty were trying relentlessly to develop adaptive methods of delivery. Arc GIS Pro and Google Earth were excellent tools that enabled the haring, edits, and modification of surficial structural features particularly in Rosendale NY and Sussex NJ where fieldtrips are traditionally held.

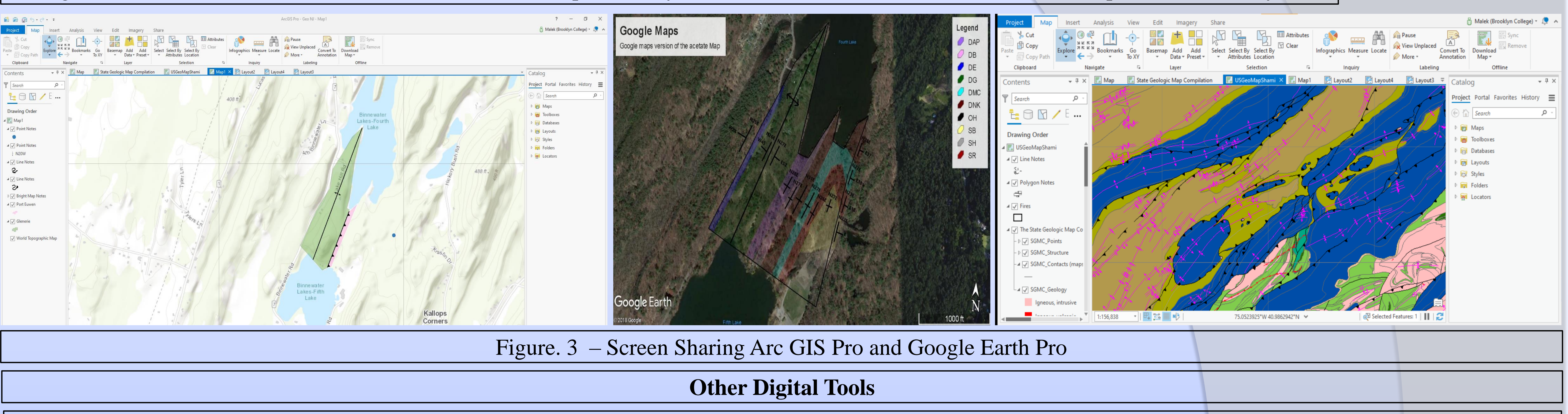

In addition to Arc GIS Pro and Google Earth, various tools via screensharing were utilized in the remote method of delivering structural geology content. Platforms such as D-Plot enabled students to integrate and plot surface elevations, topographic features, and cross sections. Due to the complexity of projecting structural and deformational features such as slickensides on a physical sample, pictures, maps, and videos were utilized as supplemental formats to aid the delivery of such materials. Student feedback varied at the beginning of the semester but ultimately, the comfort level and understanding of the materials was enhanced. In addition, edited field images from previous field trips were shared to facilitated the visualization of various folding and faulting features for the students.

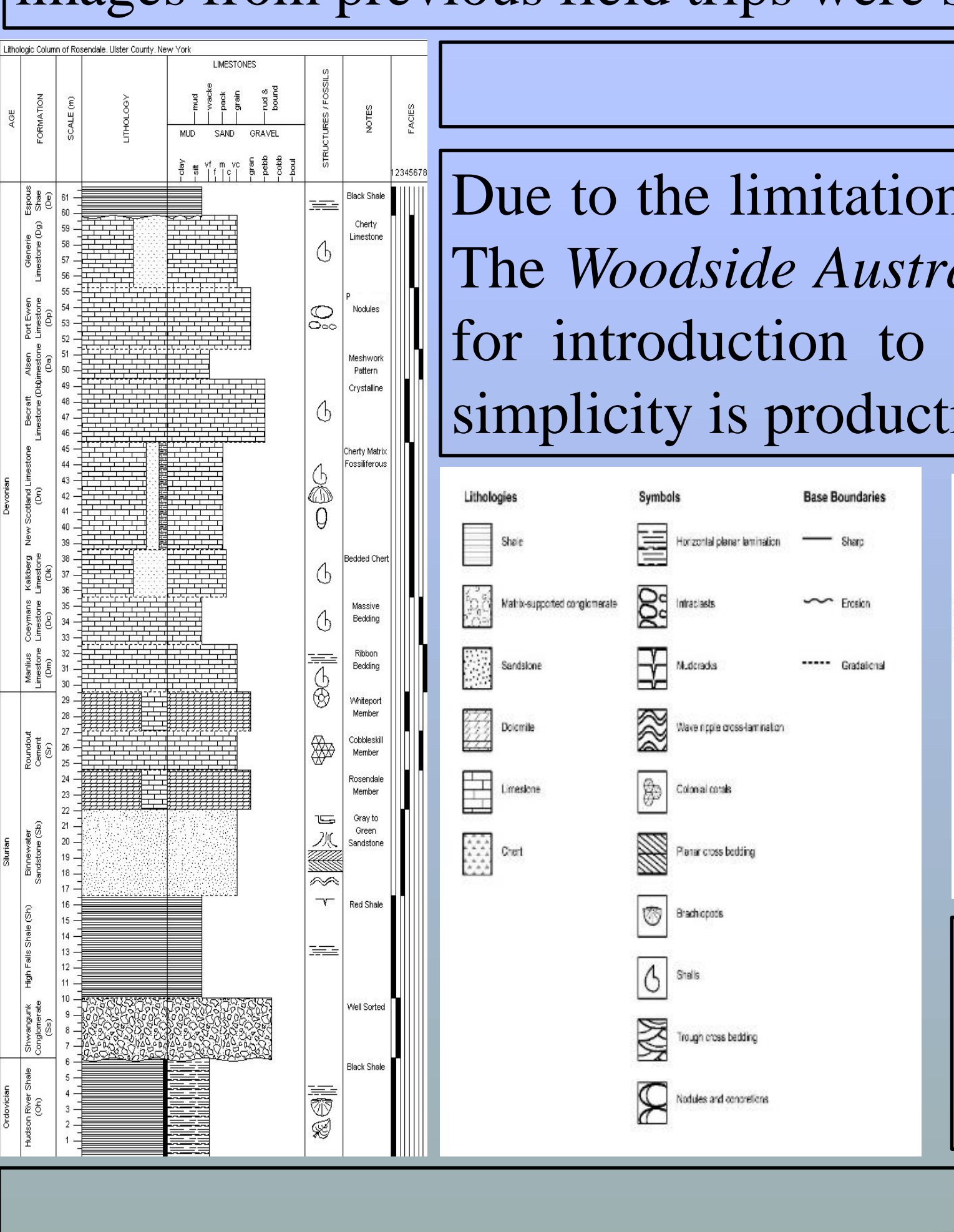

Remote Learning Supplemental Materials for Introductory Geology

in providing supplemental materials that address structural and surficial features in remote learning Se Whe surficial analysis and geologic cross-sections. While it may appear elementary, the approach and plicity is productive and can easily correlate to structural features in the field.
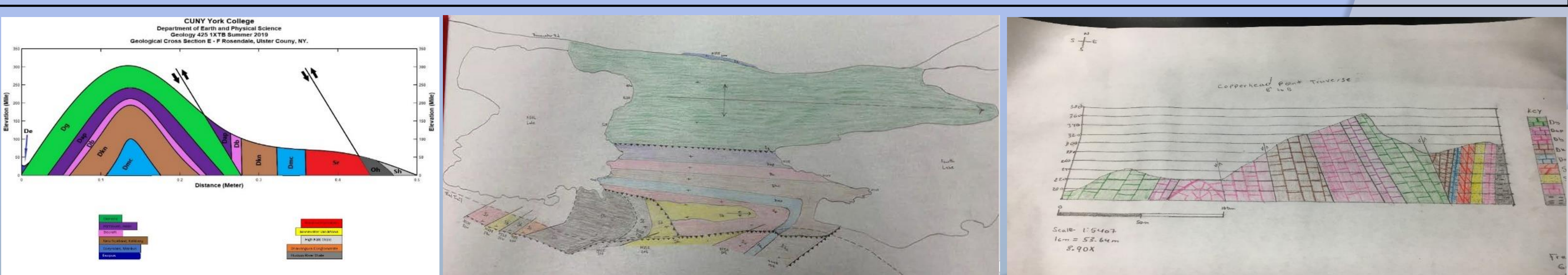

There are limitations to implanting and sharing various tools with students. A good example is the be obtain cost free.

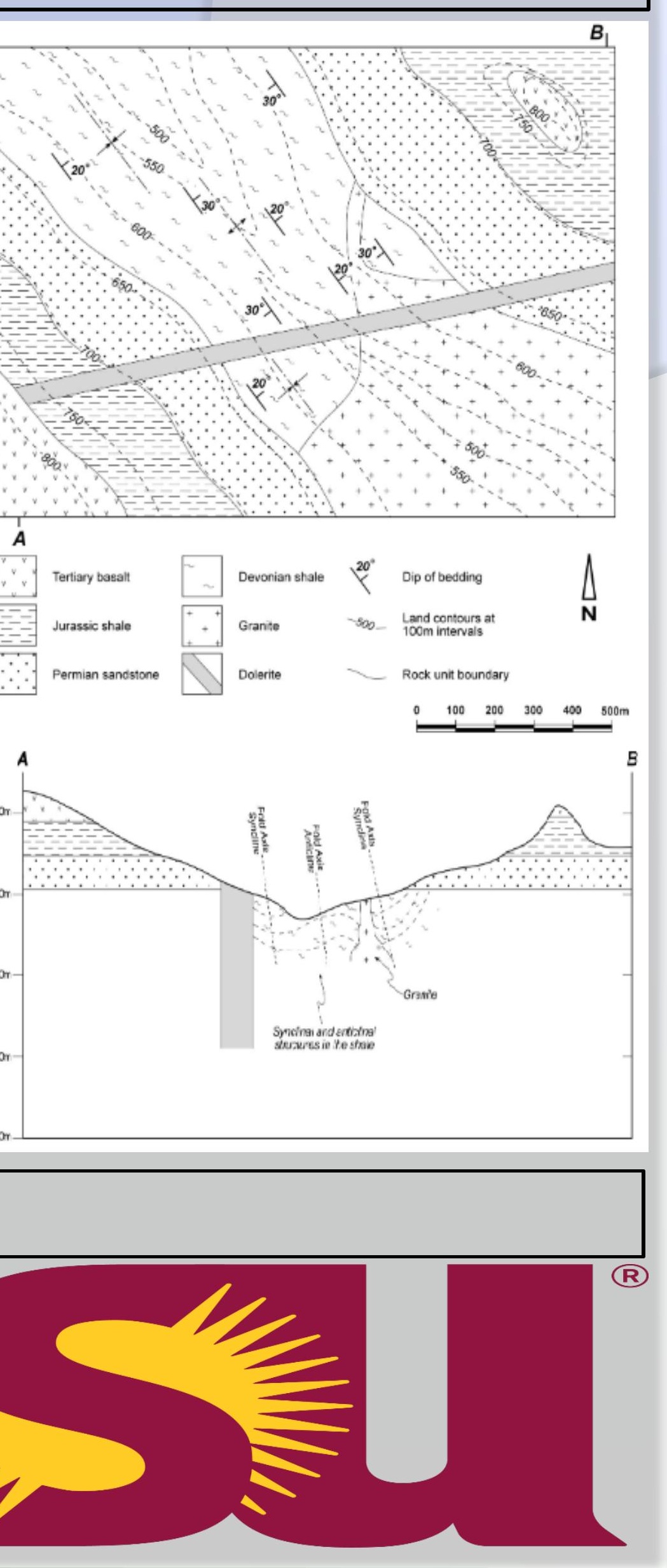

